\title{
Revalidation - what is the problem and what are the possible solutions?
}

Kerry J Breen MB BS, MD, FRACP, Adjunct Professor

Department of Forensic Medicine Monash University, Melbourne, VIC

kerry.breen@ bigpond.com

doi: 10.5694/mjal3.11261
T he aim of this article is to stimulate debate within the medical profession in Australia about the need for a revalidation process as part of renewing medical registration. The chair of the Medical Board of Australia (MBA) has been quoted as stating that revalidation is likely to be in place within 3 to 5 years. ${ }^{1}$ This risks putting the cart before the horse. The medical regulator and the medical profession might be wiser to first more clearly identify what the problem is that revalidation is intended to fix and then examine what methods might best suit that aim — points made 13 years ago. ${ }^{2}$ Similar consideration needs to take place among the other health professionals and regulators who come under the umbrella of the Australian Health Practitioner Regulation Agency.

\section{Revalidation in context - a brief history}

Revalidation is a term used by the General Medical Council (GMC) of the United Kingdom since the mid 1990s, and is closely aligned with the term "recertification", used in the United States. The International Association of Medical Regulatory Authorities has defined revalidation as "... the process by which doctors have to regularly show that they are up to date, and fit to practice medicine". ${ }^{3}$ Revalidation in the UK contains some elements in common with the Australian approach to continuing medical education (CME) and continuing professional development (CPD).

The process of revalidation commenced in the UK late in 2012 after a long and difficult gestation. ${ }^{4}$ In addition to those elements of CPD with which most Australian doctors are familiar, it involves every doctor in independent practice participating in an annual appraisal and undergoing a more detailed assessment every 5 years (http:// www.gmc-uk.org/doctors/revalidation.asp). This detailed assessment includes feedback from multiple health professional colleagues (of whom only half should be doctors) and from multiple patients. ${ }^{5}$ The UK process is decentralised, in that there are designated bodies to support the appraisal process and regional "responsible officers" or employers authorised to recommend individual doctors to the GMC for revalidation. The process may cost "tens of millions of pounds a year" as well as the unknown costs of remediation. ${ }^{4}$ The GMC estimated that early retirements due to the demands of revalidation might cause a fall in income of $\$ 3.8$ million, although it may yet be too early to determine the full effects of the scheme on doctors' decisions to retire. Between January 2013 and July 2013, 63 doctors gave up practice as a result of the revalidation scheme. ${ }^{6}$

\section{Summary \\ - The proposed introduction of a revalidation process as part of renewal of medical registration in Australia needs wide debate. \\ - The revalidation process that began in the United Kingdom in 2012 is premised on a need to regain the trust of the community and to promote participation in continuing professional development. These alone are not justifiable grounds for introducing a similar process in Australia. \\ - There are good reasons to argue that existing processes and databases should be used to determine more accurately what the weaknesses in Australia's medical regulatory regime are and to tailor improvements to those weaknesses.}

\section{Why was revalidation introduced in the UK?}

Revalidation has been consistently described as aiming to restore trust in the medical profession, support involvement in CPD and weed out bad apples. ${ }^{7}$ One proponent wrote in 1999 that "demands are growing for increasing transparency and accountability to patients in systems for ensuring doctors' standards" and called for a system to be "implemented with a 'light touch" ${ }^{8}$

The notion that revalidation was introduced to regain public trust in the self-regulated medical profession trust that had been eroded by a series of regulatory failures in the UK (most notably the Bristol and Shipman cases) has been repeatedly emphasised. ${ }^{5,9,10}$ What was a concern about the performance of the GMC appears to have been turned into an issue for the entire medical profession. ${ }^{11}$ The GMC has sought to placate the profession by promoting revalidation as a means of honouring good doctors, using language such as "the vast majority of doctors maintain a good standard of professional practice", and "revalidation should be an unobtrusive celebration of their commitment and achievement ... an open statement that they are worthy of the public's trust" ${ }^{11}$

\section{How has revalidation been received by the profession in the UK?}

The strongest criticisms of revalidation have been of its sparse evidence base. ${ }^{7,12}$ It has been claimed that revalidation will not reliably detect poorly performing doctors, and many commentators have pointed out that revalidation would not have identified Dr Harold Shipman. ${ }^{7,13}$ The medical profession in the UK appears to have accepted revalidation, albeit reluctantly, as representing the price to 
be paid for maintaining the existence of the GMC and for regaining public trust after a series of regulatory failures. ${ }^{7}$

\section{Are there equivalents of revalidation in other} developed nations?

Canadian regulators have been proactive in seeking means of assuring the community that registered doctors remain competent to practise. There is much to be learnt from Canada's experience; however, there is no single national approach in Canada, as registration is province based. ${ }^{14}$ Some provinces have mandated participation in medical college CPD programs; some have added random practice audits, which become compulsory for doctors over 70 years of age; ${ }^{15}$ some take a qualityimprovement approach; and Quebec uses interrogation of comprehensive prescribing databases to seek evidence of poor performance. ${ }^{16}$

In the US, certification of specialist training by the American Board of Medical Specialties has been time limited for over 20 years, and recertification is required. ${ }^{17,18}$ However, certification is voluntary and is not required for medical registration renewal. ${ }^{19}$ The various specialty boards have some freedom in the design of the processes for maintenance of certification. For example, the American Board of Emergency Medicine uses a combination of open-book examinations, CME points, a high-stakes secured examination once every 10 years, completion of an approved practice-improvement program, and feedback on communication and professionalism. ${ }^{20}$ The US specialty boards have put much effort into computer-based systems that are intended to test more than just clinical knowledge. ${ }^{21}$ Encouragingly, there is some evidence that certification is associated with higher standards of medical care, ${ }^{22}$ but the US system is not without fierce critics ${ }^{23-26}$ (see also http://www.changeboardrecert.com).

The New Zealand Medical Council has required recertification since 2001. In 2010 the Council described its approach as "supporting and promoting excellence and professionalism" and required attestation to 50 hours of CPD per year, including a clinical audit, 10 hours of peer review and 20 hours of CME. ${ }^{27}$ It has since added a requirement for regular practice reviews (http:// www.mcnz.org.nz/maintain-registration/recertificationand-professional-development).

\section{Does Australia need a revalidation process?}

There is little to support the idea of simply transposing the UK system to Australia. Despite some local failures of medical regulation and hospital governance, there has been no widespread loss of faith of the community either in its doctors or in the regulatory system. In addition, the culture and values of Australian patients and doctors and the nature of our health care system differ significantly from the UK. These differences can be readily exemplified by the absence of any requirement for patients to be registered with a general practitioner and the existence of a readily accessible health care complaints system.
The MBA would be wiser to start afresh by asking and answering two questions - namely, is there a problem with medical registration in Australia that needs attention, and, if so, what should be done to fix the problem? It is not sufficient to simply assert that the community expects that registration ensures that all doctors are competent and practise medicine safely, that current registration processes cannot provide such assurance, and that revalidation will provide it. It seems illogical and unnecessarily costly to introduce an additional layer of assessment of all doctors when there is general agreement that most doctors strive to maintain and enhance their knowledge and skills and are rarely the subject of complaint. This is even more problematic without an evidence base to indicate that revalidation will achieve its stated aim.

\section{Is there a problem with medical registration?}

Undoubtedly, a small proportion of doctors are not as competent as is demanded or expected of them. Many such doctors are detected via the health complaints system. Are there others who are not detected? Nobody knows. As Hawkes wrote in the UK context, "the conundrum is how to identify these doctors without subjecting the rest to time consuming and needless procedures". ${ }^{4}$ Ideally, they should be identified as early as possible and helped to improve their performance. This should be a collective responsibility of all in the medical profession. Thus, the real issue for the regulator and the medical profession is how to best identify at-risk doctors and seek remediation or their removal from the register. Australian doctors have participated in CME and CPD programs for decades, but it is still not known if genuine participation is associated with improved performance or fewer complaints. In the absence of that information, it would be reckless to invest resources in a revalidation scheme.

\section{How can answers be found?}

Since 2010, every Australian-registered doctor who seeks to renew his or her registration each year must attest to participation in a program of CPD that meets the required standard (http://www.medicalboard.gov.au/ Registration-Standards.aspx). Returns are compulsory and subject to audit by the MBA and the medical colleges (which are responsible for virtually all CPD programs). Although the precise nature of CPD programs varies between medical colleges, common components include participation in medical education events, audit, peer review, teaching, and self-education through reading, research or other study. The resulting annual returns from these well developed CPD programs provide a valuable database that could be used to help answer many questions. For example, data from this source could be linked to complaints data or other evidence of poor performance and perhaps thereby answer the question of the value of compulsory CPD.

A second approach to providing evidence of the value of compulsory CPD could be through detailed analysis of doctors whose competence is called into question via pathways including complaints and litigation for alleged 
negligence. Already, such analysis has revealed that only a small number of doctors who attract multiple complaints are the subjects of the bulk of complaints. ${ }^{28}$ It would be a small step to examine whether lack of participation in CPD was a factor in these recidivists.

A third approach might be to begin to build up profiles of doctors at higher risk of unsatisfactory performance. In Canada, this led to some provinces routinely assessing the practices of doctors reaching the age of 70 years. ${ }^{15}$ Research may well show other at-risk groups, such as those who practise in isolation from colleagues and peers, those who have been subjects of multiple complaints or certain categories of complaint, and those recovering from illness, including substance misuse.

\section{Are there any predictors of complaints?}

If receipt of multiple complaints is a reliable flag for poor performance, are there any predictors for which doctors are most likely to be complained about? One factor identified in a Canadian study as a predictor of complaints to medical regulatory authorities was poor performance in the communication component of national licensing exams. $^{29}$ Doctors' length of time in practice and clinical experience might also be associated with complaints. It is a common assumption that performance improves with clinical experience, but studies have given conflicting results. ${ }^{30,31}$ A systematic review of the literature came to the conclusion that "physicians who have been in practice for more years and older physicians possess less factual knowledge, are less likely to adhere to appropriate standards of care, and may also have poorer patient outcomes". ${ }^{32}$

\section{What other gaps in knowledge are there?}

When a doctor is found to be practising at a substandard level and is deemed to need remedial action, what are the underlying causes of such a situation? Assuming that at some earlier point in their careers such doctors were indeed competent, what has happened to change that situation? The possibilities are multiple and include burnout, mental illness, family and other stresses, physical illness affecting cognition, ageing and longstanding ill suitedness to medical practice. Having a national database should provide the MBA with the opportunity to explore these questions and thereby help in targeting preventive measures.

\section{Options for improving processes}

Assuming that some of the above factors are at play, then the following options might become attractive. As part of good governance of hospitals, performance appraisals conducted on a regular basis, or when reappointment or renewal of privileges is sought, might identify doctors in need of assistance. ${ }^{33}$ Health checks for older doctors seeking hospital reappointment could also be considered.

Medical board experience is that poorly performing doctors usually lack awareness of their plight. Even competent doctors are not good at self-assessment. ${ }^{34}$ One facet of the UK revalidation model, the use of multisource feedback from colleagues and patients, could be investigated in Australia by one or more of the medical colleges in collaboration with the MBA. Research into the most effective ways to gain feedback on doctors' performance is needed to determine appropriate feedback mechanisms for the Australian context. Negative feedback should guide targeted improvement strategies.

However, the most attractive immediate option for the MBA might be targeted assessment of the competence of doctors believed to be at highest risk of poor performance. Research indicates that appropriate targets may be doctors who have been the subject of more than one substantiated complaint, and older doctors. If this approach is taken, the next question is: are there tools fit for the purpose of such assessment? One study has suggested that measurement of "insightful practice" fits this need. ${ }^{12}$ However, other researchers have urged caution in the use of multisource feedback, particularly if it is to be used as a summative tool (ie, for decisions about recertification). ${ }^{35}$ Used as a formative tool, it might help to focus CPD efforts. It has been welcomed by participants who believe that it has helped them to improve their practice. ${ }^{36,37}$

Beyond this, research needs to answer questions such as whether remediation can help the poorly performing doctor, what form remediation might take and who will pay for it. There are good reasons for arguing that existing processes and databases should be used to determine more accurately what the weaknesses in Australia's medical regulatory regime are and to tailor improvements to those weaknesses. Revalidation as part of renewal of medical registration in Australia needs to be debated widely among the MBA and members of the medical profession in Australia.

Acknowledgements: Dr Kerry Goulston and Dr Paul Nisselle kindly commented on a draft of the manuscript.

Competing interests: No relevant disclosures.

Provenance: Not commissioned; externally peer reviewed.

1 Kaye B. Revalidation may target older GPs. Medical Observer 2013; 18 Mar. http://www.medicalobserver.com.au/news/revalidation-may-target-olderGPs (accessed Nov 2013).

2 Newble D. GMC's proposals for revalidation. Purpose of revalidation process must be agreed on. BMJ 2001; 322: 358.

3 International Association of Medical Regulatory Authorities. Glossary. Regulatory terms. Revalidation. http://www.iamra.com/ glossary.asp\#revalidation (accessed Jan 2014).

4 Hawkes N. Revalidation seems to add little to the current appraisal process. BMJ 2012; 345: e7375.

5 Rubin P. Commentary: the role of appraisal and multisource feedback in the UK General Medical Council's new revalidation system. Acad Med 2012; 87: 1654-1656.

6 Bradley A. UK revalidation fears are yet to eventuate. Australian Doctor 2013; 2 Aug: 8. http://www.6minutes.com.au/news/latest-news/revalidationdoesntdeterukdoctors (accessed Jan 2014).

7 Greenhalgh T, Wong G. Revalidation: a critical perspective. Br J Gen Pract 2011; 61: 166-168.

8 Southgate L, Pringle M. Revalidation in the United Kingdom: general principles based on experience in general practice. BMJ 1999; 319: 1180-1183.

9 Dyer C. Have we heeded the lessons from Shipman? BMJ 2010; 341: c5711.

10 Pringle M. Revalidation. Br J Gen Pract 1999; 49: 259-260.

11 Beecham L. UK doctors' revalidation should be linked to registration. BMJ 1999; 318: 349A.

12 Murphy DJ, Guthrie B, Sullivan FM, et al. Insightful practice: a reliable measure for medical revalidation. BMJ Qual Saf 2012; 21: 649-656.

13 Lowenthal L. Revalidation will not reliably detect poorly performing doctors. BMJ 2012; 345: e8009.

14 Levinson W. Revalidation of physicians in Canada: are we passing the test? CMAJ 2008; 179: 979-980.

15 Dauphinee WD. Revalidation of doctors in Canada. BMJ 1999; 319: 1188-1190. 
16 Theman TW, Oetter HM, Kendel DA. Revalidation of Canadian physicians. CMAJ 2009; 180: 539.

17 Levinson W, King TE, Goldman L, et al. American Board of Internal Medicine maintenance of certification program. NEng J Med 2010; 362: 948-952.

18 Levison W, Holmboe E. Maintenance of certification: 20 years later. Am J Med 2011; 124: 180-185.

19 Levinson W, Holmboe E. The reply. Am J Med 2012; 125 (1): ell.

20 Nelson RN. Demystifying maintenance of certification. Ann Emerg Med 2013; Mar 8. [Epub ahead of print.] doi: 10.1016/j.annemergmed.2013.01.025.

21 Hawkins RE, Weiss KB. Commentary: building the evidence base in support of the American Board of Medical Specialties maintenance of certification program. Acad Med 2011; 86: 6-7.

22 Sutherland K, Leatherman S. Does certification improve medical standards? BMJ 2006; 333: 439-441.

23 Brisson P. The value of recertification. Am J Surg 2010; 199: 724.

24 Volpintesta EJ. Common sense and the recertification process. Am J Med 2012; 125: e9.

25 Wu J. A piece of my mind. Recertification. JAMA 2010; 303: 309-310.

26 Norcini JJ. Recertification in the United States. BMJ 1999; 319: 1183-1185.

27 Pigou P. Clarification of MCNZ's role. N Z Med J 2010; 123: 103-104.

28 Bismark MM, Spittal MJ, Gurrin LC, et al. Identification of doctors at risk of recurrent complaints: a national study of healthcare complaints in Australia. BMJ Oual Saf 2013; 22: 532-540.
29 Tamblyn R, Abrahamowicz M, Dauphinee D, et al. Physician scores on a national clinical skills examination as predictors of complaints to medical regulatory authorities. JAMA 2007; 298: 993-1001.

30 Fajardo Dolci G. [Malpractice and physician's age] [Spanish]. Gac Med Mex 2011; 147: 266-269.

31 Birkeland S, Christensen Rd, Damsbo N, Kragstrup J. Patient complaint cases in primary health care: what are the characteristics of general practitioners involved? Biomed Res Int 2013; 2013: 807204. doi: 10.1155/2013/807204. Epub 2013 Aug 21.

32 Choudhry NK, Fletcher RH, Soumerai SB. Systematic review: the relationship between clinical experience and the quality of health care. Ann Intern Med 2005; 142: 260-273.

33 Miller A, Archer J. Impact of workplace based assessment on doctors' education and performance: a systematic review. BMJ 2010; 341: c5064.

34 Davis DA, Mazmanian PE, Fordis M, et al. Accuracy of physician selfassessment compared with observed measures of competence: a systematic review. JAMA 2006; 296: 1094-1102.

35 Campbell JL, Roberts M, Wright C, et al. Factors associated with variability in the assessment of UK doctors' professionalism: analysis of survey results. BMJ 2011; 343: d6212.

36 Finlay K, McLaren S. Does appraisal enhance learning, improve practice and encourage continuing professional development? A survey of general practitioners' experiences of appraisal. Oual Prim Care 2009; 17: 387-395.

37 Hill JJ, Asprey A, Richards SH, Campbell JL. Multisource feedback questionnaires in appraisal and for revalidation: a qualitative study in UK general practice. Br J Gen Pract 2012; 62: e314-e321. 